\title{
Carcinoma of stomach and breast with lymphoid stroma: localisation of Epstein-Barr virus
}

\author{
K Horiuchi, K Mishima, M Ohsawa, K Aozasa
}

\begin{abstract}
Aims-To determine the presence of Epstein-Barr virus (EBV) genome in six patients (three with gastric and three with breast carcinoma) with severe small lymphoid cell infiltration.

Methods-The polymerase chain reaction and in situ hybridisation were used to detect EBV genome. The number and distribution of $T$ and $B$ lymphocytes were evaluated by immunohistochemistry.

Results-Histologically all of the patients had poorly differentiated tumours. Immunohistochemistry showed that $T$ cells predominated in three cases, $B$ cell in two, and almost equal numbers in one case. PCR showed that the EBV genome was present in two cases each of gastric and breast carcinoma. In situ hybridisation for EBV genome provided positive signals only in the small lymphoid cells in one gastric and two breast carcinomas giving a positive reaction for $\mathrm{EBV}$ genome by PCR. The gastric and breast cancer cells did not give positive signals.

Conclusion-Severe lymphoid cell infiltration in gastric and breast carcinoma does not necessarily indicate that these tumours are associated with EBV. Larger numbers of cases will need to be studied to confirm this.
\end{abstract}

(F Clin Pathol 1994;47:538-540)

An oncogenic role for Epstein-Barr virus (EBV) in B cell lymphoma and nasopharyngeal carcinoma has been suggested. ${ }^{1}$ Recent studies have shown the presence of EBV sequences in carcinoma cells of the thymus, ${ }^{2}$ stomach, ${ }^{3}$ and salivary gland. ${ }^{4}$ The EBV related epithelial tumours have generally shared common morphological features (poorly differentiated tumour cells accompanied by severe lymphoid cell infiltration-so-called lympho-epithelioma). Gastric lympho-epithelioma-like carcinoma is thought to be similar to the gastric carcinoma with lymphoid stroma reported by Watanabe et al in $1976 .{ }^{5}$

Gastric carcinoma with lymphoid stroma is relatively rare and constitutes about $4 \%$ of all gastric carcinomas. ${ }^{6}$ Because these patients survive longer than those without lymphoid stroma, ${ }^{35}$ the infiltration by small lymphoid cells in the tumours has been interpreted as a host reaction to the tumour. Therefore, there are two theories on the cause of carcinomas with lymphoid stroma: one is a central role for EBV, resulting in the lympho-epithelioma- like pattern; the other is a host reaction to tumour growth. In the present study, the presence of EBV genome in three cases each of gastric and breast cancer showing severe lymphoid cell infiltration in and around the tumours was studied by using the polymerase chain reaction (PCR) and in situ hybridisation, originally established by us as a highly sensitive method. ${ }^{6}$

\section{Methods}

Three patients with gastric carcinoma and three with breast carcinoma showing massive infiltration of lymphoid cells in and around the primary tumour were selected for study. All patients were treated by surgical resection of tumour. Histological specimens were fixed in $10 \%$ formalin and routinely processed for paraffin wax embedding.

Sections, cut at $4 \mu \mathrm{m}$, were stained with haematoxylin and eosin. The tumours were classified according to the "General Rules for Gastric Cancer Study" or "General Rules for Clinical and Pathological Recording of Mammary Cancer" (Fapan). ${ }^{8}$ The avidin biotinperoxidase complex staining procedure was used. Sections were incubated with normal horse serum for 30 minutes and incubated overnight at $4^{\circ} \mathrm{C}$ with mouse antihuman antibodies Mx-PanB(CD20) (Kyowa Medex, Tokyo; diluted at 1 in 50); MB-1, MT1(CD43) (Bioscience, Emmenbrucke; 1 in 50); and UCHL-1 (Dakopatts, Copenhagen; 1 in 100). Subsequent reactions were accomplished using a VectaStain avidin biotinperoxidase complex kit (Vector Laboratories, Burlingame, California, USA). The peroxidase reaction was blocked in phosphate buffered saline ( $\mathrm{pH} 7.4$ ) containing $0.005 \%$ $\mathrm{H}_{2} \mathrm{O}_{2}$ and $0.03 \%$ 3', 3-diaminobenzidine tetrahydrochloride.

PCR

DNA was extracted from formalin fixed, paraffin wax embedded tissues. PCR was performed using heat-stable Thermus thermophilus (Tth) DNA polymerase (Toyobo, Osaka, Japan). Primers and probes were synthesised using a DNA synthesizer (391 DNA synthesiser) and purified in an Oligonucleotide Purification Cartridge (Applied Biosystems, Foster, California). EBV primers were located in the long internal repeat 1 , used previously by Uhara et al. ${ }^{9}$ The PCR products were electrophorosed on $2 \%$ agarose gel and visualised with ethidium bromide staining under ultraviolet light. The gel was transferred on to a nylon membrane and hybridised with the ${ }^{32} \mathrm{P}$ end labelled specific oligonucleotide probe.
Correspondence to: Dr Katsuyuki Aozasa Accepted for publication 7 September 1993 
Table Clinical and pathological findings in six patients

\begin{tabular}{|c|c|c|c|c|c|c|c|}
\hline $\begin{array}{l}\text { Case } \\
\text { No }\end{array}$ & Age & Sex & $\begin{array}{l}\text { Site and size } \\
\text { of tumour } \\
(\mathrm{cm})\end{array}$ & $\begin{array}{l}\text { Macroscopic } \\
\text { appearances }\end{array}$ & Surgery & $\begin{array}{l}\text { Depth of } \\
\text { invasion }\end{array}$ & $\begin{array}{l}\text { Lymph } \\
\text { node } \\
\text { metastasis }\end{array}$ \\
\hline \multicolumn{8}{|c|}{ Gastric cancer } \\
\hline 1 & 74 & $\mathrm{~F}$ & Angle & Fungating & Partial gastrectomy & Subserosa & No \\
\hline 2 & 42 & $\mathbf{M}$ & Corpus & Early cancer & Wide extent gastrectomy & Submucosa & No \\
\hline 3 & 54 & $\mathbf{F}$ & Corpus antrum & Ulcerated & Total gastrectomy & Serosa & Yes \\
\hline \multicolumn{8}{|c|}{ Breast cancer } \\
\hline 4 & 42 & $\mathrm{~F}$ & UIQ $(2.5 \times 2.5)$ & Mass & Radical mastectomy & & No \\
\hline 5 & 54 & $\mathrm{~F}$ & UOO $(3 \times 3)$ & Mass & Radical mastectomy & & No \\
\hline 6 & 49 & $\mathrm{~F}$ & UIQ $(2.5 \times 2)$ & Mass & Radical mastectomy & & No \\
\hline
\end{tabular}

UIQ upper inner quadrant: UOQ upper outer quadrant.

As positive controls, pellets of Raji cells and an EBV positive Burkitt's lymphoma cell line were examined. A pellet of Ramos cell, derived from EBV negative Burkitt's lymphoma cells, was used as negative control for EBV. Raji and Ramos cells were provided by the Japanese Cancer Research Resources Bank (JCRB) (Tokyo).

\section{IN SITU HYBRIDISATION}

Recently we established a highly sensitive in situ hybridisation procedure using digoxigenin-11-dUTP labelled probe using PCR. ${ }^{6}$ With this method, we were able to examine the localisation of EBV genomes in tissue sections. Using 12 sets of primers, the Bam H1-W fragment of EBV was amplified with labelled substrate in individual PCRs. The 12 probes, with an average size of 120 base pairs, were mixed together and hybridised with the histological sections. Cytospin specimens of the EBV positive cell line, Raji (gift of $\mathrm{Dr} H$ Mizusawa, National Institute of Hygiene) and the EBV negative cell line MT-1 (gift of the Japanese Cancer Research Resources Bank, Tokyo) were hybridised with the probes. Numerous dots were observed over the nucleus of the Raji cells. No signals could be found in MT-1 cells. The specificity of the probes and the staining were evaluated by the following control studies: (1) the slides were incubated with the hybridisation buffer containing unlabelled DNA, subsequently incubated with antigen to digoxigenin antibody-alkaline phosphatase conjugate and its substrate; (2) signals were observed using digoxigenin labelled probe for JD, repeat sequence of mouse gene. This probe was prepared by random primed labelling, as described above.

\section{Results}

The clinical and pathological findings of the six patients are summarised in the table. All of the gastric carcinomas were poorly differentiated adenocarcinoma. Depth of invasion had extended beyond the muscularis propria in two cases and within the submucosa in one. All of the mammary carcinomas were classified as invasive solid tubular carcinoma. The lymphoid stroma consisted of small lymphoid and plasma cells in every tumour, with lymphoid follicle formation in one gastric carcinoma (case 2). Eosinophils were common in three gastric carcinomas and neutrophils in one (case 1). Small lymphoid cells had invaded the cancer cell nests in one gastric (case 2) and one breast carcinoma (case 4). Immunohistochemical staining showed that B lymphocytes outnumbered $T$ lymphocytes in two cases (cases 2 and 4); T lymphocytes predominated in three (cases 1,3 , and 5), with an almost equal number of both subsets in one case.

The PCR method showed that the EBV genome was present in two (cases 2 and 4 ) out of three gastric and two breast carcinomas (cases 4 and 6) (figure).

In situ hybridisation for the EBV genome provided positive signals in the small lymphoid cells in one case of gastric (case 3 ) and two of breast carcinoma (cases 4 and 6) with a positive reaction for EBV genome by the PCR. The signals were observed as a few dots in the nuclei. No signals were detected in the gastric and breast carcinoma cells.

\section{Discussion}

The PCR showed that about $70 \%$ of the gastric and breast carcinomas in this series contained EBV genome; this high positivity rate of EBV agreed with previously published findings on undifferentiated carcinoma with severe lymphoid infiltration of the salivary gland, ${ }^{4}$ thymus, ${ }^{2}$ and stomach. ${ }^{3}$ Using in situ hybridisation, a previous study had shown that the EBV genome was localised in the carcinoma cells of salivary gland ${ }^{4}$ and stomach. ${ }^{3}$ However, Min et al ${ }^{10}$ reported that in situ hybridisation failed to define the presence of the EBV genome in three cases of gastric carcinoma with EBV genome, confirmed by PCR, in the tumour tissues. In our study positive EBV genome signals were detected by in situ hybridisation only in the small lymphoid cells. The gastric and breast carcinoma cells never gave positive signals.

The present cases of carcinoma with severe lymphoid cell infiltration superficially resemble the previously reported cases showing similar morphological features. These tumours had undifferentiated or poorly differentiated morphology. All of our cases were poorly differentiated carcinomas. Shibata $e t a^{3}$ reported that their cases of undifferentiated carcinoma with intense lymphoid infiltration were similar to the gastric carcinoma with lymphoid stroma described by Watanabe et al. ${ }^{5}$ 
(A) Severe infiltration of lymphocytes around poorly differentiated

adenocarcinoma of the stomach (haematoxylin and eosin).

(B) Agarose gel

electrophoresis of $E B V$ and $H T L V-1$ DNA amplified with specific primers.

Positive results are shown by the band at 128 base pairs in the lanes showing Raji cells and case 2 (EBV). HTLV-1 DNA was not amplified, except for one patient (ATL), used as a positive control, at 189 base pairs.

Southern blot analysis of the gel with

${ }^{32}$ P-end labelled specific oligonucleotide probes shows hybridisation with the PCR product of Raji cells in case 2 (EBV primer), and one patient ( $A T L)$ (HTLV-1 primer).

(C) In situ hybridisation of case 2 shows $E B V$ sequences in small lymphocytes but not in cancer cells (methyl green counterstain).

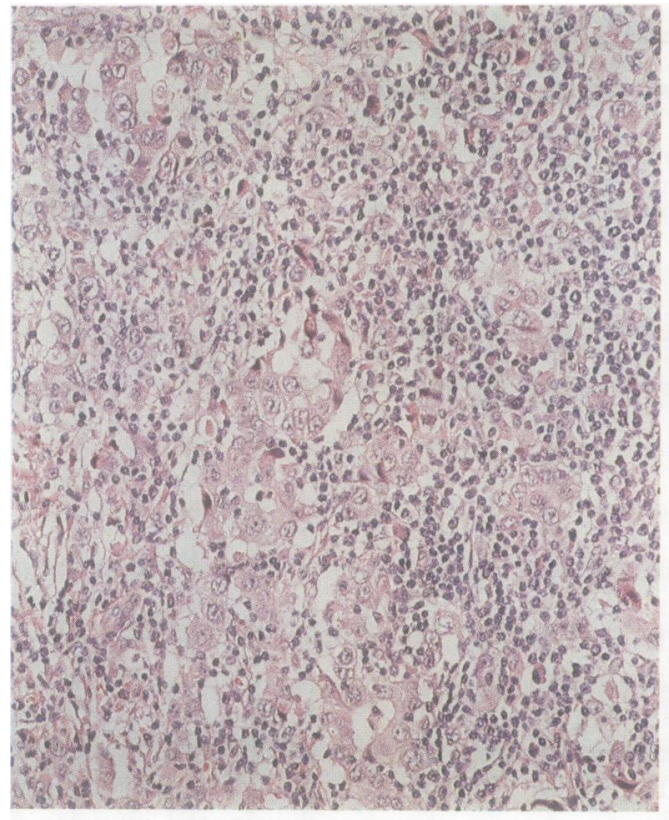

(A)
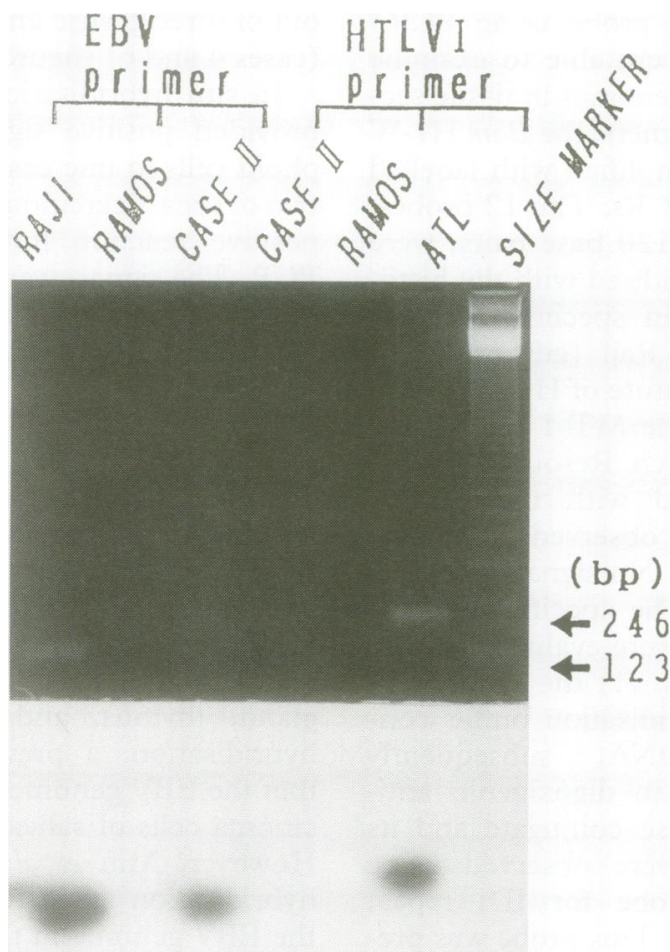

(B)

Meanwhile Watanabe et al ${ }^{5}$ reported the presence of limited areas of differentiated adenocarcinoma in 12 of 42 cases.

The immunological characteristics of the infiltrating lymphoid cells in carcinoma with severe lymphoid cell infiltration have seldom been mentioned before. Min et al reported that most of the lymphocytes surrounding cancer cell nests in their cases of gastric cancer were $T$ cells. ${ }^{10}$ It is well known that patients with undifferentiated carcinoma showing severe lymphoid cell infiltration survive longer than those without. ${ }^{3510}$ In our

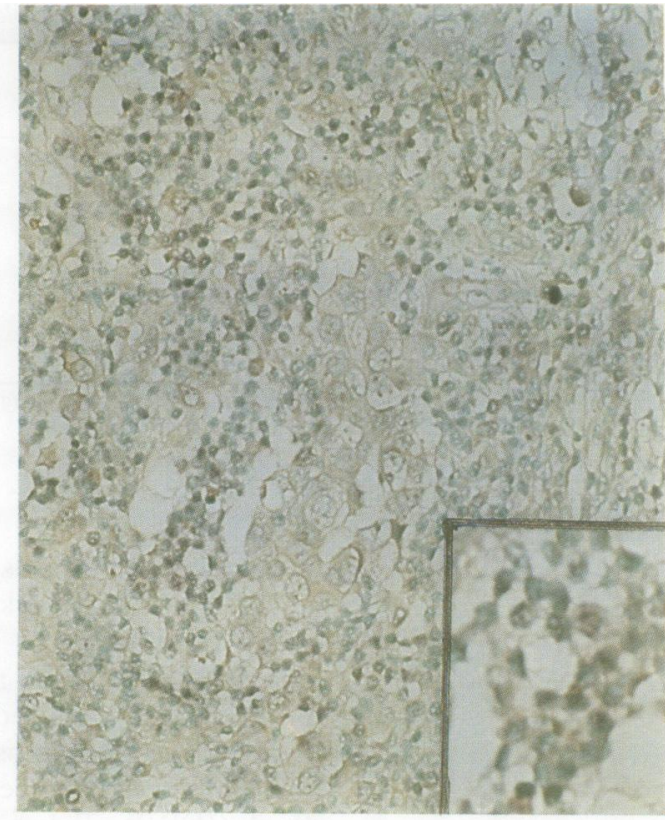

(C)

cases, the $T: B$ cell ratio was not constant; $T$ cells predominated in three cases and $\mathrm{B}$ cells in two cases. Although the follow up was short, our patients did not show a favourable prognosis: two out of six died within two years.

In conclusion, this study has shown that severe lymphoid cell infiltration in gastric carcinoma, and possibly breast carcinoma, does not necessarily indicate that these tumours are neoplasms related to EBV. Because of the small numbers studied, more cases need to be investigated.

We thank Professor E H Cooper for helpful comments, Y Fukui for technical assistance, and Y Matsumoto for typing the manuscript.

1 Zur Hausen H, Schulte-Holthausen HS, Klein G, et al. EBV DNA in biopsies of Burkitt tumors and anaplastic carcinomas of the nasopharynx. Nature 1970;228: 1056-8.

2 Leyvroz S, Henle W, Chahinian AP, et al. Association of Epstein-Barr virus with thymic carcinoma. $N$ Engl $f \mathrm{Med}$ 1985;312:1296-9.

3 Shibata D, Tokunaga $\mathrm{M}$, Uemura $\mathrm{Y}$, et al. Association of Epstein-Barr virus with undifferentiated gastric carcinoma with intense lymphoid infiltration. Lymphoepithelioma-like carcinoma. Am f Pathol 1991;139: 469-74.

4 Hamilton-Dutoit SJ, Therkildsen $\mathrm{MH}$, Nielsen $\mathrm{NH}$, et al. Undifferentiated carcinoma of the salivary gland in Greenlandic Eskimos: Demonstration of Epstein-Barr Greenlandic Eskimos: Demonstration of Epstein-Barr
virus DNA by in situ nucleic acid hybridization. Hum virus DNA by in situ

5 Watanabe H, Enjoji M, Imai T. Gastric carcinoma with lymphoid stroma. Its morphologic characteristics and prognostic correlations. Cancer 1976;38:232-43.

6 Saeki K, Mishima K, Horiuchi K, et al. Detection of low copy number of Epstein-Barr virus by in situ hybridization by non-radioisotopic probes by polymerase chain reaction. Diagnost Mol Pathol 1993;2:108-15.

7 Japanese Research Society for Gastric Cancer. The General Rules for Gastric Cancer Study. 11 th edn. Tokyo: JRSGC, 1985.

8 Japan Mammary Cancer Society. General Rule for Clinical and Pathological Record of Mammary Cancer. 9th edn. Tokyo: JMCS, 1988.

9 Uhara H, Sato Y, Mukai K, et al. Detection of EpsteinBarr virus DNA in Reed-Sternberg cells of Hodgkin's disease using the polymerase chain reaction and in situ hybridization. Ipn $¥$ Cancer Res 1990;81:272-8.

10 Min K-W, Holmquist S, Peiper SC, O'Leary TJ. Poorly differentiated adenocarcinoma with lymphoid stroma (lymphoepithelioma-like carcinomas) of the stomach. (lymphoepithelioma-like carcinomas) of the stomach.
Report of three cases with Epstein-Barr virus genome demonstrated by the polymerase chain reaction. $A m \mathcal{F}$ Clin Pathol 1991;96:219-27. 